\title{
UTÓPICAS CIDADES DE NOSSAS ANDANÇAS: \\ FLÂNERIE E AMIZADE NO ACOMPANHAMENTO TERAPÊUTICO ${ }^{\star}$
}

Analice de Lima Palombini ${ }^{\star \star}$

\section{ReSUMO}

Com base na experiência do acompanhamento terapêutico como uma clínica sem muros, imersa na cidade, o artigo centra-se no tema da cidade nas suas relações com a subjetividade. Valendo-se das elaborações de Benjamin sobre a flânerie e a idéia da amizade como política, presente em Foucault e Derrida, o texto assinala a importância, para a consecução dessa clínica, de se tomar em consideração a cidade como polis, aberta ao encontro com a diferença e, portanto, território de conflitos e negociação. Assim, a cidade como polis é a utopia que a clínica do acompanhamento terapêutico busca ativar.

Palavras-chave: Acompanhamento terapêtico; cidade; amizade.

\section{UTOPIAN CITYS OF OUR WALKS:}

\section{FLÂNERIE AND FRIENDSHIP IN THE THERAPEUTIC ACCOMPANIMENT}

\begin{abstract}
The article, based on the experience of therapeutic accompaniment as a clinic without walls immersed in the city, focuses on the issue of the city and its relations to subjectivity. Using the elaborations of Benjamin about the flanerie and the idea of friendship as the politic present at Foucault and Derrida it underscores the importance, for the achievement of this clinic, of taking into account the city as polis, open to the encounter with difference and therefore a territory for conflict and negotiation. Thus the city as polis is the utopia that the clinic of therapeutic accompaniment intends activate.
\end{abstract}

Keywords: therapeutic accompaniment; city; friendship.

$\star$ Parte deste artigo corresponde à pesquisa de doutorado realizada com auxílio PICDT/CAPES.

$\star \star$ Psicóloga. Possui mestrado em Filosofia pela Universidade Federal do Rio Grande do Sul e doutorado em Saúde Coletiva pela Universidade Estadual do Rio de Janeiro. Professora do Instituto de Psicologia da UFRGS, vinculada ao PPG em Psicologia Social e Institucional. Endereço: Universidade Federal do Rio Grande do Sul, Instituto de Psicologia. Avenida Ramiro Barcelos 2600 sala 132. São Manoel. CEP. 90035-003 - Porto Alegre, RS - Brasil.

E-mail: analice.palombini@ufrgs.br 
A melhor maneira de conhecer uma cidade é perder-se nela. Perder-se numa cidade, diz Benjamin (1995[1987]), requer instrução. ${ }^{1}$

Em 1840, Edgar Allan Poe (1993[1850]) abandona o conforto da observação envidraçada e fria da massa informe que serpenteia pelas calçadas londrinas e mergulha na noite da cidade seguindo os rastros do homem na multidão. Charles Baudelaire (1985[1860]) não hesita em abandonar à lama o halo de poeta que lhe cai da cabeça em meio ao caos do tráfego urbano da Paris de 1865: razões de sobrevivência o impelem, mas também, o prazer de experimentar a mundanidade. Walter Benjamin $(2000 ; 2006)$, fiel a seu próprio ensinamento, na primeira metade do século XX deixa-se errar pelo labirinto de ruas em que se perfilam seus achados sobre a Paris oitocentista. Nos anos 1990, Michel de Certeau (1994), em Manhatan, sobe (premonitoriamente?) ao $110^{-}$andar do World Trade Center para, fugindo das ruas e do rumor de tantas diferenças que se lançam nelas, querer ser apenas um ponto que vê, voyeur colocado à distância, dominando a gigantesca massa que, do alto, se imobiliza: "Será necessário depois cair de novo no sombrio espaço onde circulam multidões que, visíveis lá do alto, embaixo não vêem? Queda de Ícaro". Ítalo Calvino (1990[1972]), fazendo recuar a cidade visível, recorre ao narrador-viajante da tradição para inventar uma profusão de cidades que, invisíveis, escapam aos guias turísticos e aos projetos urbanísticos (ancoradas em Veneza, cidade de origem, que a cada vez se rememora e se esquece, elas multiplicam virtualidades e potencialidades para que a cidade utópica possa existir). Rubem Fonseca (2004[1992]) perambula pelo centro do Rio de Janeiro para escrever sobre a arte de andar por suas ruas, à procura de uma melhor comunhão com a cidade, que só se pode obter andando, solvitur ambulando.

Andemos, então, pela cidade, inicialmente guiados por Benjamin, deixando-nos errar pelo traçado de suas linhas, seguindo as pistas que nos ajudam a ler a cidade que nos habita e aquela que acompanhantes terapêuticos, ${ }^{2}$ imbuídos da arte de andar pelas ruas, desbravam.

\section{É A CIDADE QUE HABITA OS HOMENS OU SÃO ELES QUE MORAM NELA?}

Próprias da cidade moderna, a multiplicidade, polifonia e pulsação - expressa, num primeiro momento, no surgimento do fenômeno da multidão - levantam suspeitas e temores entre a burguesia nascente que a habita. É em oposição a tais espaços que são construídas as suas casas, como reduto da intimidade e proteção, na vã tentativa de dividir casa e mundo, interior e exterior, aconchego e risco (BAPTISTA, 2005) ${ }^{4}$ despolitizando a vida doméstica e encerrando o indivíduo em si mesmo e na família (D'ANGELO, 2006). No interior do lar burguês, rituais domésticos e objetos de decoração cultuam a ilusão de um universo harmonioso, bem ordenado, esquecido das contradições da sociedade. ${ }^{5} \mathrm{O}$ mesmo não ocorre com as classes populares, cuja habitação - densamente povoada - leva a um uso privativo do espaço público e é apontada como fonte de perturbação da ordem pública, de instabilidade política e de problemas sanitários ao longo de todo o século XIX (D’ANGELO, 2006). 
Nos anos 1850, sob os auspícios de Napoleão III, Haussmann, prefeito de Paris, empreende o maior de todos os projetos de reurbanização dos tempos modernos, motivado pela urgência de garantir a liberdade individual de ir e vir e assim reprimir as desordens provocadas pelos movimentos de massa. ${ }^{6}$ Demolese a Paris medieval. Novas vias, retas e largas, atravessam os bairros operários, dividindo suas comunidades e ligando os distritos ao centro da cidade. Parques são remodelados, ao mesmo tempo em que uma gigantesca rede subterrânea de esgoto é instalada. Ferro e vidro são os novos materiais de construção, com os quais se erguem as passagens e o mercado central de Paris, templos de um consumo emergente (SENNETT, 1997; BENJAMIN, 2006).

$\mathrm{Na}$ interpretação de Benjamin (1989), a reconstrução levada a cabo por Haussmann se faz especialmente notável por materializar a confluência entre o antigo e o moderno, em razão da fragilidade do presente, tornado efêmero pelo próprio ato de renovar-se. Conforme a descrição de Gagnebin (2004, p. 50), "a 'reurbanização' de Paris destrói bairros inteiros, apaga o labirinto das ruazinhas medievais, abre grandes avenidas e alamedas 'modernas', num gesto arquitetônico no qual ruínas e fundações se confundem". A busca incessante do novo faz da cidade uma construção ao mesmo tempo triunfante e frágil: "a morte não habita só os palácios de ontem, mas já corrói os edifícios que estamos erguendo" (GAGNEBIN, 2004, p. 50). ' As passagens parisienses, surgidas nos primeiros decênios do século XIX como notável novidade, ${ }^{8}$ mas perdendo, logo em seguida, seu prestígio e função, constituem uma das realidades concretas que, para Benjamin, expressam a marca da modernidade, essa "obsolescência sempre mais acelerada das inovações e invenções que se originaram das forças produtivas do capitalismo em desenvolvimento" (TIEDEMANN, 2006, p.16).

O flâneur - personagem que emerge das páginas da literatura urbana do século XIX, com Poe, Baudelaire, Dickens, Victor Hugo, Balzac - é o habitante por excelência das passagens parisienses, é o que usufrui das experiências limiares e paradoxais que nelas têm curso: intermezzo entre a rua e a casa, novidade que se arruína, grande salão dessa morada do coletivo em que se tornam as ruas, ${ }^{9}$ nas passagens oflâneur vagueia em meio à multidão, fora de casa, mas à vontade como se em casa estivesse; sentindo-se olhado por tudo e por todos, centro do mundo, mas também vendo a tudo e a todos, escondido, insondável em seu meio; descobrindo um país exótico e distante, mas que não é outro senão aquele, bem perto, no qual vive (BENJAMIN, 1989).

A cidade inteira torna-se passagem para o flâneur, cindida em seus dois polos dialéticos: "abre-se para ele como paisagem e, como quarto, cinge-o" (BENJAMIN, 1989, p.186), pois a flânerie tanto pode transformar toda Paris num interior quanto pode levar a cidade a se abrir diante do transeunte como "uma paisagem sem soleiras" (BENJAMIN, 1989, p.192). ${ }^{10}$ E, então:

[numa espécie de embriaguez] a cada passo, o andar ganha uma potência crescente; sempre menor se torna a sedução das lojas, dos bistrôs, das mulheres sorridentes 
e sempre mais irresistível o magnetismo da próxima esquina, de uma massa de folhas distantes, de um nome de rua (BENJAMIN, 1989, p.185).

Alegoria de uma modernidade desbravada, erguida a ferro e vidro pelo capitalismo em meio às ruínas e vestígios do passado, o passeio do flâneur pela cidade o conduz a um tempo desaparecido, tecendo-se de forma que, tal como os sonhos, o evento de hoje liga-se a um outro mais remoto. As ruas que o flâneur percorre, nas quais ressoam os seus passos, são feitas das camadas de tempo a que pertencem os prédios que nelas se perfilam, tão próximos uns dos outros, por mais que os separem os intervalos da história. No ponto para o qual confluem as ruas de uma cidade, no qual, em geral erguem-se as suas praças, desembocam também as correntes de sua história (LION apud BENJAMIN, 1989).

Para o flâneur, afirma Benjamin (1989), todas as ruas são íngremes, descem em direção ao passado - o da cidade e o seu próprio. Mas, esclarece Gagnebin (2004), esse passado que oflâneur colhe em seu passeio apenas pode retornar numa não-identidade consigo mesmo, marcado que foi pela "ação corrosiva da história e do tempo" (GAGNEBIN, 2004, p. 44). A retomada do passado no tempo presente revela-se, então, "abertura sobre o futuro, inacabamento constitutivo" (GAGNEBIN, 2004, p.14) que recusa a totalidade enganosa contida seja na ideia de progresso, seja na de um passado mítico originário: aquilo que guardam as ruínas, os destroços, os fragmentos dispersos no emaranhado histórico que constitui a cidade é o que permite transcender a ordem social dada em direção a uma realidade transformada, redimida (GAGNEBIN, 2004). ${ }^{11}$

Para Benjamin, portanto, o caráter paradoxal do novo - incessante e fadado a uma destruição próxima - faz da modernidade o lugar ao mesmo tempo de uma catástrofe e de uma possibilidade de redenção. Catástrofe e redenção, nos termos propostos por Benjamin, concernem à cidade como sonho coletivo, que, expressando em imagens oníricas sua realidade objetiva, requer interpretação. $\mathrm{O}$ trabalho das Passagens, ${ }^{12}$ nesse sentido, trata de colocar em relevo as expressões oníricas da vida material na Europa do século XIX, que o fenômeno do capitalismo fez mergulhar num "sono povoado de sonhos" (BENJAMIN, 2006, p. 436). A moda, a arquitetura, o jogo, a prostituta, o urbanismo à moda de Haussmann, a iluminação a gás, o transporte, as exposições universais, o grande magazine, o lixo, as barricadas, as passagens, o flâneur, são imagens do sonho oitocentista, cuja interpretação cabe ao historiador, de forma a arrancar o coletivo de seu sono, iluminando, no instante do despertar, o caráter dialético dessas imagens, entre o mito e a utopia.

Benjamin toma de empréstimo a concepção freudiana sobre o trabalho do sonho para pensar, por um lado, as forças produtivas e as relações de produção que se referem à infraestrutura econômica como constituindo o 'corpo' do sonhador, que se exprime na superestrutura da mesma forma que os sinais somáticos se exprimem na consciência do sonhador. Trata-se, para o autor, de conceber a vigência de uma expressão da economia, em seus pormenores, nos traços singulares de uma cultura, em lugar da ideia de uma gênese econômica global da cultura. (BENJAMIN, 2006; ADORNO; BENJAMIN apud NOBRE, 1997; ROUANET, 
1992). Por outro lado, as imagens do sonho coletivo são - como o sonho freudiano - imagens de desejo, com as quais se busca lidar com o inacabamento e as imperfeições da ordem social, transcendendo (aufheben) e dissimulando (verklaeren) uma realidade insatisfatória. (BENJAMIN, 2006; ROUANET, 1992). Enquanto a Aufhebung fica a cargo da utopia, ${ }^{13}$ a Verklaeren (dissimulação da realidade e dissimulação das representações que incorporam o desejo) é empreendida pelo mito, inibindo o que a utopia tenta liberar (ROUANET, 1992, p. 47).

A dialética das Passagens, então, tanto contém a realidade em sua polaridade objetiva e onírica, quanto envolve a tensão e interpenetração, no polo onírico, entre mito e utopia - entre as fantasmagorias aderidas a um passado mítico, que buscam perpetuar-se e eternizar o sono, e o sonho utópico "que contém o desejo e impele em direção ao despertar" (ROUANET, 1992, p.47), impele a um salto fugaz para o futuro pela "superposição entre o agora e o ocorrido" (BOLLE, 2006, p. 1159).

O passeio do flâneur dá a ver, em uma profusão de detalhes, a materialidade de que é feita Paris, especialmente entre os anos 1830 a 1870: suas ruas, arquitetura, construções de ferro e vidro, número de lampiões a gás, bairros, linhas de ônibus, lojas e mercadorias, bolsa de valores, lixo, rede de esgotos, metrô, barricadas, prostituição... Mas a minúcia do olhar que lhes dirige o flâneur, longe de ater-se à descrição cabal de sua realidade objetiva, visa antes o alcance de sua dimensão onírica, como mito e utopia. Assim, descreve Rouanet (1992, p. 69-71), o emaranhado de ruas se faz labirinto, animado seja pelo "desejo de chegar", a utopia de "alcançar o objetivo", seja pelo perigo mítico do perder-se, de "não chegar ao fim" ou chegar a um fim não desejado; os lampiões a gás iluminam "o sonho da cidade-luz", utopia da "cidade iluminista" onde resplandecem a ciência e a liberdade e mito do encantamento luminoso da mercadoria, "luz néon da indústria cultural"; o tráfego, com suas linhas de ônibus, transporta "o sonho utópico da ubiquidade" e "o sonho mítico da imobilidade forçada no caos urbano da cidade repressiva"; o grande magazine exibe tanto a "utopia da mercadoria oferecida a todos" como o "mito que escraviza as massas ao consumo"; o lixo que o trapeiro recolhe é, ao mesmo tempo, "símbolo utópico da redenção, quando todos os detritos serão salvos, recolhidos por um grande colecionador" e "símbolo mítico do trabalho degradado".

Cada objeto da cidade, das ruas aos cafés e às pontes, cada atividade, da moda ao jogo e à prostituição, cada personagem, tanto os reais, como Haussman, Fourier e Baudelaire, quanto os alegóricos, como o jogador, o colecionador e nosso velho conhecido, o flâneur, tudo o que a cidade contém e a própria cidade, absolutamente tudo está mergulhado no sonho, e como tal tudo é ambivalente (...) apontando para a salvação e para a catástrofe, para o sempre igual do mito e para o verdadeiramente novo da redenção (ROUANET, 1992, p. 71). 
Percorrendo o trabalho das passagens de Benjamin, Rouanet responde duplamente à pergunta que dá título a esta seção: os homens habitam, sim, a cidade, objeto real, entidade concreta com suas ruas, praças, sistemas de transporte; os homens são habitados, sim, pela cidade de sonho, entidade onírica que mora neles. É da passagem de uma a outra que se ocupa a obra monumental de Benjamin em torno à cidade do século XIX, obra que, como a história de que trata, é para sempre inacabada, feita de fragmentos, ruínas, citações, lampejos que se oferecem à interpretação do historiador a fim de que a dimensão utópica do sonho encontre os meios para se transformar em práxis, minando sua fantasmagoria.

As quatro décadas centrais do século XIX em Paris, das quais se ocupa Benjamin e que o flâneur percorre em seu passeio - da revolução de 1830 à instalação do Segundo Império em 1852 e à Comuna de Paris, em 1871 -, contêm o essencial da história da Modernidade, focalizando o que Hobsbawn (apud BOLLE, 2006) chamou de passagem da Era das Revoluções (1789-1848) para a Era do Capital (1848-1875) que prepara a Era dos Impérios (1875-1914). Nesse cenário, Paris, metrópole de um império colonial, desponta, luminosa e fervilhante, como "capital do século XIX". A coletânea de fragmentos que Passagens reúne constitui-se, assim, em um dispositivo potente para a leitura das redes de poder que, no contemporâneo, enlaçam a periferia do mundo ao centro da metrópole e que irradiam, às megacidades do Terceiro Mundo, o "desvario" e o "inferno", o mito e a utopia, já presentes na "capital do século XIX" (BOLLE, 2006, p. 1165).

\section{Cidades, andanças, amizade}

Uma característica bastante peculiar ao acompanhamento terapêutico, ao AT, é o fato de que o seu exercício se dá "entre" lugares, o que pode significar "entre um dentro e um fora", "entre a casa e a rua". Com muita frequência, o "at" é solicitado justamente nos casos em que a circulação pela via pública se encontra impossibilitada, com sujeitos cuja existência mantém-se confinada ao espaço exíguo de um quarto, em meio a uma atmosfera pesada e asfixiante. É preciso, então, "primeiro, ocupar o quarto, explorar possibilidades e lugares psíquicos, antes que a geografia da cidade" (PALOMBINI, 2002, p.64). Mesmo em tais casos, a cidade, a rua, mantém-se, invariavelmente, no horizonte desse trabalho.

A cidade, seus cheiros, ruídos, história, perpassa o quarto através das frestas das janelas (e nas telas midiáticas), por entre os poros de suas paredes [...], a cidade se encontra no quarto em cada coisa pequena que ele contém, em cada objeto humilde de que se faz uso nele (PALOMBINI, 2002, p. 67).

Assim, essa cidade que o "at" percorre não se concebe tão somente como "palco" da clínica, ou como seu elemento acessório, que vem dar concretude e permanência a conteúdos psíquicos de frágil consistência. Na experiência do AT, na medida em que se desbravam ruas, cantos, quartos, a cidade adquire um outro vulto, revelando-se a potência contida na incorporação, pela clínica, de cada 
um dos gestos e objetos que compõem o cotidiano urbano. ${ }^{14} \mathrm{~A}$ cidade, os seus espaços e tempos, restos e monumentos, em sua rica variabilidade, passam a ser concebidos como "matéria constitutiva" e primeira dessa clínica.

A figura do flâneur, que Benjamin nos apresenta como alegoria do século XIX e de sua modernidade, ilustra um certo modo de relação com a cidade que podemos aproximar da perspectiva que liga o AT ao espaço urbano: a dissolução dos limites entre interior e exterior (ou entre interioridade psíquica e realidade objetiva); a estrangeiridade com que se experimenta o que é familiar; o passeio por tempos desaparecidos, corroídos pela história, e que são retomados, no agora, para compor novos futuros, sempre inacabados; o andar distraído, à deriva, que se deixa levar pelo acaso mas que, ao mesmo tempo, dedica, aos detalhes que se revelam em seu percurso, às suas minúcias, toda a agudeza e sagacidade de que pode o olhar. O trapeiro, cuja figura, assim como a do flâneur, Benjamin recolhe em especial das páginas de Baudelaire, também responde ao espírito do que se propõe o AT: ao longo do percurso que traça pelas ruas, apanha restos, trapos, fragmentos da história; coleta e transfigura os objetos rejeitados, perdidos, quebrados que a cidade abandonou; resgata-lhes um sentido, atribui-lhes novos usos e contextos.

Contudo, tanto o flâneur como o trapeiro entregam-se a uma experiência em geral solitária, o que não é absolutamente o caso na relação do AT com a cidade. A respeito da solidão do flâneur, Benjamin registra uma passagem de Romains (Le crime de Quinette - Les hommes de bonne volonté, II) que aponta a amizade como o seu antídoto, por meio da qual um segredo fugidio do mundo, dando-se a ver uma única vez e ainda que se tratando de algo pequeno, pode ser presenciado e compartilhado por dois amigos.

Imagine, por exemplo, dois homens que passeiam, como nós. E, de repente, graças a uma fenda entre as nuvens, uma luz vem bater no alto de um muro, e o alto do muro se transforma por um instante em algo de extraordinário. Um dos homens toca o ombro do outro, que ergue a cabeça e vê o mesmo, compreende o que aconteceu. Depois a coisa se desmancha no ar. Mas eles saberão in aeternum que ela existiu (ROMAINS apud BENJAMIN, 2006, p. 487-488; BENJAMIN, 1989, p. 222).

O tema da amizade não é mais retomado por Benjamin ao longo de suas reflexões sobre o flâneur - em meio a outros assuntos, ele dedica-se, antes, a descrever as relações do flâneur com a massa uniforme da multidão ou com os tipos anônimos que nela despontam. Porém, à maneira do trapeiro, colhemos essa breve citação como quem, em meio a tantos fragmentos que compõem as suas Passagens, esbarra em um pequeno tesouro. A experiência do AT, com efeito, apenas pode realizar-se se alia a atitude própria à flânerie ao que aqui propomos chamar de o exercício da amizade. No entanto, o que se designa por amizade, nesse contexto, escapa ao modo como esta é concebida pelo senso comum ou em textos filosóficos consagrados sobre o assunto. A forma da amizade que pode servir à experiência do AT não é aquela, vivida na esfera da intimidade e das identifi- 
cações, que iguala o amigo ao irmão, ao semelhante, espelho da alma do outro; ao contrário, é como diferença, distância, assimetria - sem recusa à solidão imanente à incomensurabilidade entre o eu e o outro - que a amizade faz-se presente à dinâmica do acompanhamento, numa agonística que, pondo em questão certezas e crenças, incita à transformação e inventa formas não prescritas de existência.

Assim, se, no acompanhamento a César, em sua perambulação pelas ruas do centro, Eliane se fez presente como o amigo a que se refere a citação de Romains - alguém que presencia e compartilha os acontecimentos ínfimos e fugidios que só aos dois, no coração da cidade, é dado ver -, isso foi feito sem que se apagassem as diferenças que, de um a outro, tensionavam e davam sustentação ao encontro que protagonizavam. Em um desses momentos de tensão, Eliane, fazendo valer o que ambos haviam combinado, recusou-se a deixar que César se fosse antes da hora, levando-o a se confrontar, dessa forma, com as consequências da intempestividade de seus atos. César reagiu à atitude de Eliane, avançando sobre ela, dedo em riste: "eu te pego, hein. Tu não é nada minha" (como a lhe lembrar que nenhum laço de parentesco os unia). Eliane, sem ceder à ameaça, respondeu que era, sim, alguma coisa dele, era sua 'at' (o que compreende um laço para além do espaço privado da família). Ao final do ano, no término do acompanhamento, César dizia a Eliane da importância que tiveram, para ele, aqueles encontros: "tu me escutou" (JOVER, 2004, p. 70). Escutado em sua diferença, afetado pelo outro que - amigo, mas não igual - o acompanhava, César experimentava de um jeito novo a cidade de suas andanças.

Conforme Derrida (1998), o exercício da amizade como celebração da diferença é uma experiência marcada pela inconstância e imprevisibilidade, aberta, portanto, para o novo e para a invenção. Sendo, além disso, uma relação assimétrica, não encontra estabelecidos, de antemão, os lugares em que se posicionam cada um de seus membros, o que faz parte do jogo estratégico em que se movem, para o qual não cabem nem prescrições nem predições. A cena relatada por Tibulo (2003) o revela bem. Acompanhando Lúcia em seu passeio costumeiro pelo parque em frente ao CAPS em que se atendia, viu-se impedida de com ela andar no trenzinho que percorre o lugar, devido à chuva forte que começava a cair. Buscando proteção na bilheteria do trem, as duas tiveram a companhia do rapaz que deveria conduzi-lo, que logo foi entabulando conversa com a dupla, mostrandose vivamente interessado por Ana Paula, a at .Nessa ocasião, Lúcia que se encarregou de conduzir a cena, ao contrário do que ocorria, frequentemente, quando se limitava a seguir os passos de Ana Paula pelo parque, incapaz de decidir o rumo a tomar. Ela não titubeou em fazer perguntas e responder, com fina ironia, às que eram feitas pelo rapaz, defendendo Ana Paula das suas investidas. E, quando ele perguntou o que elas faziam no CAPS, respondeu, senhora de si: "a gente trabalha, a gente escreve". Depois de um tempo de conversa, como a chuva não cessasse, o rapaz ofereceu-lhes uma carona de trenzinho até a frente do CAPS. Lá, Lúcia contou aos demais usuários e técnicos que as duas haviam andado de trenzinho de graça e que "ainda tive que cuidar dessa guria", referindo-se a Ana Paula e ao 
fato de que o condutor do trem pretendia "paquerá-la". "Essa dupla é arretada!" comentou um dos usuários, e Lúcia arrematou a conversa dirigindo-se à sua acompanhante: "Foi uma aventura, né, Ana Paula?" e "vou escrever sobre isso".

Por fim, cabe evocar a relação entre eros e philia que, recusada ao longo da história, é retomada por Foucault, para quem, mediante a variabilidade no uso dos prazeres, torna-se possível multiplicar relações, criando novos códigos relacionais e inventando formas novas de vida. Foucault (1994[1981], p. 38), por esse viés, investe no tema da amizade valendo-se da relação homossexual para pensar a amizade como uma relação em aberto que requer invenção, pois, para além da consumação do ato sexual, "como é possível para homens estarem juntos? viver juntos, compartilhar seus tempos, suas refeições, seus quartos [...]? o que é isso de estarem entre homens 'nus', fora das relações institucionais, de família, de profissão [...]?”. Podemos transpor a questão para o contexto da relação estabelecida entre acompanhante e acompanhado, cujo contrato é suficientemente aberto para nele fazer caber a variabilidade dos modos, lugares, situações e enredos em que se desenvolve o trabalho: como é possível para acompanhante e acompanhado estarem juntos? compartilharem seus tempos, refeições, o espaço de uma sala ou quarto? o que é isso de estarem um diante do outro fora do quadro institucionalizado do setting terapêutico tradicional?

A psicanálise ensina que o amor é um dos motores da transferência que liga analisante e analista, pondo em movimento a experiência da análise (FREUD, 1976[1915]). ${ }^{15}$ Contudo, a experiência do AT não conta com as salvaguardas próprias ao setting analítico, visando à abstenção do analista perante a demanda de amor que lhe é dirigida. A presença do "at" no cotidiano de vida do seu acompanhado, a proximidade física que entre eles se estabelece, os afetos suscitados nas experiências compartilhadas ao longo do trabalho, exigem a invenção de formas próprias de sublimação (ou ascese) do caráter sexual do erotismo, sem recusa ao prazer que da relação possa advir. O conceito platônico de eros-philia, que propõe eros sublimado como motor da amizade, pode ser útil, nesse sentido, para uma concepção do AT como exercício político da amizade, sem incorrer nas armadilhas do amor. Mas a formulação de Foucault (2004[1984]) acerca da possibilidade de invenção de novos usos e formas de prazer não necessariamente sexuais, ${ }^{16}$ que se reporta à sua noção de amizade implicada na criação de novos códigos relacionais, parece descortinar um leque talvez mais amplo de possibilidades criativas de relação e formas de existência que se forjariam na experiência do AT. ${ }^{17}$

Ao longo de oito meses, Tatiana acompanhou Artur e pôde testemunhar os efeitos notáveis que os encontros que mantinham iam produzindo nele, diferente do que se observara no acompanhamento anterior, ao qual ele pouco comparecera. Artur, desejoso da companhia de Tatiana, a quem dizia amar, ansiando por ser alguém aos olhos dela, abria cada vez mais brechas no círculo apertado e engolfante da relação até então mantida com sua mãe. Com delicadeza, sem recusar o afeto que lhe era dedicado, Tatiana conduziu a relação com Artur de modo que o amor que este lhe declarava alcançasse outros objetos ou outros fins, resultando em muitas conversas, um almoço para dois preparado por ele, na sua participação ao violão durante a festa no CAPS, no contato com uma menina por meio de uma 
sala de chat. A mãe de Artur, porém, parecia suportar mal o modo como a relação de seu filho com Tatiana ia abrindo possibilidades outras de relação dele com o mundo. Num certo momento, ela disse claramente a Tatiana que esperava que seu filho pudesse conquistá-la, mas que ele fracassara nisso - baseando-se em histórias que dizia serem reais, ela mostrava-se convencida de que a cura de seu filho dependia de que ambos, Artur e Tatiana, "paciente e psicóloga", apaixonassem-se um pelo outro. Apesar dos muitos movimentos que produziu ao longo do acompanhamento, Artur permanecia enredado no imaginário materno, que o incitava a tomar sua "at" como objeto sexual, cuja conquista significaria sua cura. ${ }^{18}$

Um outro tipo de experiência teve lugar no acompanhamento de Antonio, feito simultaneamente por Shari e Vitor (ISIDRO; SILVA, 2006), a partir da unidade de internação em que Antonio se encontrava já há um tempo demasiado longo, em virtude da dificuldade de sua inserção no meio familiar, marcado por um regime de muita violência, caos e sexualização das relações. Na enfermaria, Antonio, com frequência, investia sexualmente contra os demais internos, os quais costumavam reagir violentamente ao seu intento. Logo que teve início o acompanhamento, Antonio passou a referir-se a Shari, na unidade, como sua namorada, ao mesmo tempo em que, para Shari, dizia querer arrumar uma namorada. Quando saíam juntos os três, Antonio, Shari e Vitor, este último tinha a sensação de estar "sobrando". Quando apenas um ou outro dos acompanhantes se fazia presente, a pretensa conotação sexual do encontro criava um bloqueio para o acompanhamento. Por um tempo, a situação foi vivida como um incômodo para a dupla de acompanhantes, até tornar-se possível, aos dois, tomar o sexual como elemento do jogo estratégico instituído entre os três. Assim, se Shari era visada por Antonio como suposta namorada, tratava-se, para Shari de, encarnando a personagem, apresentar a Antonio possibilidades outras de prazer, mediadas pela palavra, pelo jogo, por uma nuança de afeto que passasse longe da violência sexual à que Antonio fôra fadado. Da mesma forma, na relação de Vitor com Antonio, os momentos de toque, de abraço, de contato afetuoso, requeridos especialmente nas situações de crise em que Antonio deixava seu corpo, literalmente, desfalecer, configuravam a possibilidade de uma relação prazeirosa com outro homem sem recurso à investida sexual.

\section{As CIDAdes do AT: A AMIZADE COMO POLÍTICA}

Os dois livros sobre AT primeiramente escritos e publicados no Brasil, ambos organizados pela Equipe de Acompanhantes Terapêuticos de A Casa, expressam, já nos seus títulos, a ênfase da cidade como forma de abordagem da experiência do acompanhamento. ${ }^{19}$ A rua como espaço clínico (1991) e Crise e cidade (1997) certamente se escrevem conforme ao contexto cultural e político em meio ao qual a prática do AT é então exercida entre nós, como mostra a análise que realiza Reis Neto (1995). Ao mesmo tempo, o pioneirismo e o alcance dessas publicações transformaram-nas em um instrumento potente de disseminação de ideias e referências chaves para os que se dedicavam a essa prática e ao trabalho nas instituições e nos serviços substitutivos de saúde mental que começavam a se implementar, favorecendo a consolidação do tema da cidade na agenda das discussões em torno do AT. 
Podemos notar, contudo, no decurso de tempo que separa a publicação de um e outro dos livros, uma mudança em operação, que já se pode ver nas nuanças de seus respectivos títulos. O primeiro deles ( $A$ rua como espaço clínico), se traz a rua ao primeiro plano da cena do AT, mantém-na, porém, subordinada aos saberes e à prática da clínica. A cidade, como tal, não é problematizada; apresenta-se, de modo quase unívoco, como espaço de possibilitação (ou não) de encontros, de descoberta de lugares nos quais se ponha em curso a expressão da singularidade daquele que é acompanhado e sua conexão com as pessoas e os acontecimentos à sua volta. A rua se faz, então, não mais do que uma extensão do espaço da clínica. ${ }^{20}$

Crise e cidade, publicado seis anos depois, ao valer-se do conectivo $e$ para reunir seus termos, evita qualquer relação de subordinação, dependência ou oposição entre eles, abrindo espaço para as múltiplas possibilidades semânticas que resultam de sua ligação, como sugere Frayze-Pereira (1997) no primeiro dos artigos que compõem esse livro. Na sequência desses artigos, a cidade comparece com força na imagem da metrópole contemporânea, fragmentada e polifônica, confronto de mundos díspares em afetação recíproca. No encontro com a rua, a clínica desacomoda-se. O termo "crise", assim, compondo com o termo "cidade" o título, pode ser referido tanto ao desmoronar de uma subjetividade, requerendo acompanhamento para que possa colher, junto aos elementos do urbano, modos inéditos com que se fazer novos contornos, quanto à desestabilização dos saberes instituídos, aos quais o AT, tocado pela cidade, já não pode mais recorrer sem que neles se produzam transformações. Não será errado afirmar que essa dupla acepção marca as produções subsequentes em torno do AT no âmbito das três clínicas em que majoritariamente essas produções se encontram referenciadas: Lacan, Winnicott ou Deleuze e Guattari.

Mas há uma terceira acepção ainda que nos interessa destacar da conexão entre crise e cidade, quando é a racionalidade própria ao urbano que se vê perturbada pela intrusão da diferença em seus espaços. Como apontam as palavras de Frayze-Pereira (1997, p. 33), abrir-se à cidade ao habitá-la, errar por suas ruas pode ser "uma ação de resistência à lógica imposta pela modernidade contemporânea", restabelecendo "o valor de uso do espaço numa sociedade que privilegia o valor de troca", investindo na construção de novos códigos relacionais. Nessa mesma perspectiva, situamos o texto de Belloc (2005) em sua dissertação de mestrado, Ato criativo e cumplicidade, na qual trata de aproximar arte e psicanálise por meio das cenas de um AT: o autor irá sustentar que é da construção de uma nova cidade - outras casas, outros bairros - que se ocupa a experiência do AT, mediante a constituição de uma rede de relações, amarrações mais ou menos tênues que se fazem na circulação com o acompanhado, ajudandoo a situar-se, a construir um lugar possível para si, como parte dessa rede. É preciso que o "at" se desprenda, então, da cidade em que se reconhece, para que uma outra cidade possa ser habitada, uma cidade que, emergindo do encontro entre acompanhante e acompanhado, constrói-se no exato in- 
stante em que, juntos, eles a percorrem. É preciso, segue Belloc (2005), colher cada detalhe desse passeio pela cidade para que, de seus gestos mínimos, de suas quinquilharias, brote a preciosidade poética da criação de um espaço em que a diferença possa inscrever-se e, em sua diferença mesma, marcar seu lugar no mundo dos iguais.

É a dimensão do acontecimento o que se coloca em jogo, então. $\mathrm{Na}$ dissertação de mestrado de Cabral (2005), Acompanhamento terapêutico como dispositivo da reforma psiquiátrica, encontramos a referência ao acontecimento da maneira como Rajchman (1991 apud CABRAL, 2005, p. 98-99) o define:

[...] singular, inatributável ou imprevisível, implicando uma outra lógica de sentido, na qual as discordâncias levam a uma transformação; [...] é sempre o distanciamento de si, [ato de diferenciação - e não identificação que se repete sem diferença. Referido ao encontro com a alteridade, no qual algo de si é perdido], o acontecimento pode ser entendido como um corte, uma ruptura com aquilo que [...] paralisa e enclausura o sujeito em uma dada posição.

O AT, portanto, de acordo com essa leitura, é feito dos acontecimentos que emergem da interação com os espaços e tempos da cidade, numa sucessão de acasos-acontecimentos que podemos tomar - em paralelo com a regra psicanalítica da associação livre - como regra fundamental dessa clínica em movimento (CABRAL, 2005).

Araújo (2005, p. 46), cuja dissertação de mestrado - Um passeio esquizo pelo acompanhamento terapêutico: dos especialismos à política da amizade - tomou forma de livro, também descreve a experiência do AT como acontecimento - aquilo que, fazendo desviar um trajeto, ou produzindo o trajeto como desvio, faz-se encontro: "um esbarrão, um tropeço, o surgimento de uma nova imagem, de uma nova paisagem [...]". Araújo reporta-se a Deleuze, para quem o acontecimento se define como "sentido", gerado no recolhimento da diferença que se produz na passagem de um estado de coisas a outro - de forma que "desvio, sentido, acontecimento são nomes que damos aos efeitos de passagem" (ARAÚJO, 2005, p. 49). O AT, então, por meio do qual se colocam lado a lado fragmentos que, juntos, compõem paisagens sempre inacabadas, é:

\footnotetext{
[...] esse passeio entre estados que ora se dão em regimes mais concretos de coisas, ora em regimes mais abstratos de pensamentos e imaginações, ora em regimes mais sensórios-perceptivos, ora em regimes de afetos e sentimentos, ora em regimes mais conscientes, ora em regimes menos conscientes. Regimes esses que se misturam na complexidade de uma simples saída à rua. [...] O sentido que surge das passagens faz com que esses passeios façam diferença (ARAÚJO, 2005, p. 51).
} 
$\mathrm{O}$ autor situa como pertinente à clínica, e, portanto, ao AT, a questão ética sobre como ser digno d'isso que acontece, como "querer" o acontecimento em vez de maldizê-lo, transmutando ressentimentos em afirmação de vida. Pois o acontecimento "é sempre a chegada de um outro [...] que visita sem convite, que surge em sua urgência, sem aviso, sem que a casa esteja preparada, sem que as condições para o seu surgimento estejam dadas" (ARAÚJO, 2005, p. 47) - é o que Araújo depreende da leitura que faz da concepção de acontecimento em Derrida, colocado ao lado de Deleuze. Para Derrida (2004), o acontecimento se define por suas condições de "impossibilidade", isto é, como um salto que um possível realiza do impossível, de modo surpreendente, incalculável, incondicionado; ele é invenção, e não repetição do mesmo que remete ao possível no sentido clássico da palavra.

Referida como condição do acontecimento, a impossibilidade situa também, para Derrida, a experiência da amizade, à qual Araújo (2005) recorre para definir o AT, partindo da noção que Derrida apresenta de uma hospitalidade incondicional, capaz de acolher o outro em sua diferença, sem impor-lhe condições, sem regras predeterminadas, mas aberta a um processo constante de negociação, no qual a aceitação irreversível do outro, o estrangeiro, vem dar novo ar à casa. Uma tal ética da hospitalidade, mais além do instituído exige, diz Araújo, novas formas de relação, o que a faz se ligar ao tema da amizade.

O autor resgata a denominação de "amigo qualificado" com que outrora se intitulavam os ats para dela fazer ressaltar a expressão "amigo", com a qual o AT pode significar uma amizade que, não tendo uma qualidade a priori, qualifica-se pela diferença que engendra na relação: "queremos pensar uma amizade que não seja qualificada e sim qualificante ou geradora de qualidades" (ARAÚJO, 2005, p. 153). E, sendo a amizade um fenômeno público que diz respeito à proposição de novas formas de relação como nos mostra Ortega (2000) através de Arendt, Derrida e Foucault, ela pode alcançar, conforme propõe Araújo (2005), a zona comum entre clínica e política, de modo que uma "política da amizade" faz-se pertinente à "clínica" do AT.

Se política é o princípio de gestão da cidade, onde se determinarão as relações entre os que nela convivem, como pensar uma cidade em que as relações comportem o princípio diferencial a différance presente na amizade? [...] Como pensar uma política de acolhimento do louco e da marca diferencial que ele carrega tão visivelmente [...]? Não para que ele continue assim, o mesmo, intocado, numa espécie de respeito a sua individualidade; mas sim para que tanto ele quanto a sociedade possam criar derivas a partir desse estranho encontro: louco e sociedade em uma relação de amizade não identitária (ARAÚJO, 2005, p. 168-169).

Ser amigo, continua Araújo (2005), é, nesse caso, possibilitar à loucura um estatuto público que lhe é de direito, indo em busca de um espaço que não é o da intimidade, mas, sim, o da organização social, por meio da invocação 
de um novo direito relacional, da criação de uma sociedade hospitaleira ao elemento diferencial. "Uma política do talvez, da incompletude, uma política que está sempre por vir [...]” (ARAÚJO, 2005, p. 173).

\section{AT TECENDO REDES: RONDAS URBANAS}

Por que ruas nos levam o AT em suas andanças? Que redes tecem os seus itinerários? De quantas impossíveis amizades são feitos os seus caminhos?

Cláudio, acompanhado por Nithiane, pôde, pouco a pouco, abandonar a posição em que o encerrava sua família, por conta da deficiência que o marcara desde o nascimento: com 38 anos, Cláudio era "infantil", "incapaz", "dependente", por um lado, e "abstêmio", "puro", "assexuado", por outro. O AT desprendeu Cláudio da barra da saia da mãe, apresentou-lhe outros espaços, outras formas de estar no mundo: para além do serviço de saúde, a escola, o ônibus, a rua. Daí que outras possibilidades de estar no mundo e fazer rede foram-se apresentando também: as mulheres, a bebida, o jogo, o ponto de tráfico. Cláudio quis ser homem como seus irmãos, como eram os homens de sua família desde outras gerações: passou a beber, jogar sinuca e meter-se em encrencas, como a surra que levou após ter mexido com uma menina no bar improvisado em sua casa. Não foi sem desassossego que Nithiane acompanhou os passos de Cláudio no entorno de onde morava, em meio à rede de tráfico de que sua casa já era parte. Mas foi sem hesitação que, perante o serviço de saúde em que seu trabalho teve início, afirmou a necessidade de seguir em frente, estando vetado o retorno ao estado infantil em que Cláudio fora antes alojado (CAPELLA, 2008).

$\mathrm{Na}$ multiplicidade dos territórios urbanos, uma rede leva à outra: das redes de apoio e cuidado às redes de tráfico e crime. Se de início, no AT de Cláudio, tratava-se de fazê-lo advir a uma vida de relações fora do círculo apertado de um cuidado tutelar, depois foi preciso previní-lo dos riscos de transitar por essas redes de violência e ilegalidade que coabitavam o seu território. Realidade presente junto aos serviços territorializados e à boa parte da população à qual se dirigem os cuidados em saúde mental no Sistema Único de Saúde, diz do desafio enorme que se ergue diante de usuários, trabalhadores e gestores desse Sistema, na defesa de um cuidado em liberdade, requerendo articulação entre diferentes setores das políticas públicas, movimentos e atores sociais e entre saberes diversos.

Fazia já algum tempo que Luciano acompanhava Rafael, mas a conversa entre eles não rolava. "Sim". "Não". "Pode ser". Era como Rafael respondia ao que Luciano perguntava, e logo o assunto morria. Mas, naquele dia, algo diferente se passava. Sentados no banco da praça, a conversa entre os dois parecia animada. Viu-se interrompida de repente, contra a vontade de um e outro: "passa o celular, isto é um assalto!" dizia o rapaz que, vindo não se sabe de onde, mantinha-se de pé diante dos dois. Luciano não quis acreditar que a conversa que ele tanto desejara pudesse terminar assim. Estendeu a mão espalmada para o assaltante, como quem pede para esperar: "olha, só um pouquinho, a gente tá conversando... dá um tempo". Era a vez do assaltante não acreditar: "cara, eu falei que isto é um assalto, passa logo o celular!". Luciano ignorou o tom de ameaça, quis a todo custo manter 
o clima da conversa com Rafael, tentou incluir o assaltante nela: "e como é mesmo o teu nome?". É claro que o rapaz não gostou nem um pouco disso e já ia destratando Luciano quando Rafael, ouvidos atentos, chamou a atenção para a sirene do carro de polícia que passava pela rua. O assaltante deu no pé (PICOLLI, 2008).

Quando da eclosão de uma crise ou diante de atitude insólita e bizarra de seu acompanhado em "praça pública", a função do "at" pode eventualmente adquirir o caráter de proteção contra olhares intrusivos e atitudes hostis das pessoas em volta que não compreendem e rejeitam o que se passa. Na cena protagonizada por Luciano, Rafael e o assaltante, a atitude do at produziu também uma espécie de proteção do espaço de conversa e encontro instaurado entre ele e seu acompanhado. Uma proteção, então, que não tinha como alvo a reação à diferença que a loucura porta, mas que se voltava, ao contrário, ao que se tornou banal e rotineiro nas cidades, o assalto à luz do dia. Àquilo que ninguém estranha mais, e que justifica o medo e o confinamento que os habitantes de uma cidade se impõem, Luciano, o "at", respondeu de forma insólita e bizarra: pediu um tempo ao assaltante, perguntou-lhe seu nome, quis conversar - o insólito da cena desarmando o seu habitual e já esperado desfecho.

Um almoço no "Tudo pelo Social", restaurante a preço popular, era o programa combinado entre Pelé e seu acompanhante terapêutico, Ricardo. ${ }^{21}$ Chegaram cedo ao restaurante, antes mesmo da fome, de modo que resolveram caminhar pelas ruas da redondeza antes de entrar no recinto. Passavam em frente a uma obra quando foram chamados, de longe, por um dos operários, que veio em sua direção com um pacote na mão. Era uma marmita de comida: "ó aqui prá vocês [...] espera que tem mais esses bifes, tá quentinho, pode comer [...]" Ricardo e Pelé se olharam e olharam para o homem que lhes oferecia o alimento: "mas [...] a gente não tá com fome [...] pode dar prá alguém que precisa [...]". O operário ficou sem jeito: "desculpa [...] eu pensei que vocês estavam aí, na lida da vida...". Mas ele não tinha errado: Pelé e Ricardo estavam, sim, numa espécie de lida, de batalha pela vida, com a qual aquele operário, mesmo sem saber, mostrouse sensível e solidário. Aqui é a cidade que nos surpreende, na evocação de um gesto de que esquecemos, desfeito que foi pelo medo, a cobiça, a rotina. $\mathrm{O}$ acaso do encontro que se dá nas ruas, entre um operário, o "at" e seu acompanhado, permite a emergência dessa cidade esquecida, feita de homens solidários. São homens destituídos de posse os que ofertam o que não têm: "no AT não há lugar fixo, nem propriedade privada; o espaço onde acontece um AT é o chão comum e o céu aberto" (PORTO, 2008, informação verbal).

\section{RONDAS INFINITAS DE OBSTINADOS}

Em artigo publicado no jornal gaúcho Zero Hora de 18 de abril, Edson Sousa (2009) narra o movimento grevista contra os projetos de lei do governo Nicolas Sarcozy que fazem, da Universidade, um comércio. "O elemento milagroso que nos alegra pode ser simplesmente o raio do sol que, numa manhã de primavera, transfigura uma rua miserável" é a citação de Georges Bataille que dá início ao artigo, intitulado "Uma ronda utópica". Desde o dia 23 de março, 
diz o texto, professores, estudantes e funcionários da Universidade de Paris VIII revezam-se em uma caminhada ininterrupta de protesto, que não tem prazo para encerrar. "Não, a universidade não é uma empresa nem o saber uma mercadoria", é o slogan que portam ao caminhar e que se disseminou em rondas infinitas por outros distritos da cidade.

Uma ronda infinita dos obstinados é como o movimento se autoproclamou. Ronda utópica, escreve Sousa (2009), pois insiste na criação de novos espaços e carrega uma esperança obstinada.

O caminhar incessante desenha uma outra relação de forças entre manifestantes e o poder. Foi o que aconteceu com a ronda das mães da Praça de Maio em Buenos Aires, fundamental na história de resistência à ditadura na Argentina (SOUSA, 2009, Caderno Cultura, p. 2)..

É o que acontece também em cada ronda urbana em que se lançam acompanhantes e acompanhados: uma outra relação de forças entre a loucura e a cidade, novos arranjos do poder, sonho de uma cidade que não recusa a diferença.

Capturados que estamos em uma lógica utilitarista, somos tentados a abandonar rapidamente tudo aquilo cujo sentido nos escapa, anestesiando, em nós e no mundo, os atos que tentam recuperar a força milagrosa daquilo que nos surpreende como promessa de futuro. Sem esta possibilidade de sonhar com outras configurações de mundo, a vida se reduziria a uma repetição sombria. A passividade que nos aprisiona faz a alegria daqueles que usufruem soberanamente de nossa paralisia. Portanto, um dos grandes desafios de nossos tempos é manter viva a esperança de mudanças estruturais em nosso laço social[...] (SOUSA, 2009, Caderno Cultura, p. 2).

Quando pensamos sobre que clínica se faz pertinente ao AT nas cidades de nosso tempo, acreditamos encontrar nos autores que percorremos, de Walter Benjamin a Edson Sousa, uma mesma resposta: é uma clínica que não se dissocia da política, que sonha uma outra cidade e, porque sonha, não abandona suas ruas, não perde a esperança de tornar diferente o laço entre seus habitantes.

O elemento milagroso que nos alegra pode ser uma vontade de se fazer homem entre outros homens, apesar dos riscos que os cercam; a defesa cega e obstinada de um espaço de encontro e conversa; a marmita que, num meiodia, oferece-se generosa a dois passantes... Raios de sol transfigurando ruas, disso se alimentam as rondas infinitas desses obstinados que constroem, a cada passo novo, uma utopia de cidade. 


\section{Notas}

1 "Saber orientar-se numa cidade não significa muito. No entanto, perder-se numa cidade, como alguém se perde numa floresta, requer instrução. Nesse caso, o nome das ruas deve soar para aquele que se perde como o estalar do graveto seco ao ser pisado, e as vielas do centro da cidade devem refletir as horas do dia tão nitidamente quanto um desfiladeiro" (BENJAMIN, 1995[1987], p.73).

${ }^{2}$ Podemos definir Acompanhamento Terapêutico como uma clínica sem muros que se realiza no espaço aberto do urbano, acompanhando cotidianos de vida de forma a favorecer o estabelecimento de laços entre o sujeito acompanhado e o território por ele habitado. O acompanhamento terapêutico busca alargar os modos de habitar a cidade, para que nela a diferença possa ter lugar. Na seqüência, utilizaremos a abreviação AT para acompanhamento terapêutico e "at" para acompanhante terapêutico.

3 “É a cidade que habita os homens ou são eles que moram nela?" é uma das sete perguntas que deram forma ao simpósio promovido pelo Instituto Goethe de São Paulo, em 1990, e que resultou na publicação do Dossiê Walter Benjamin pela Revista USP em 1992. Para a pergunta em questão, foram convidados a formular suas respostas Sérgio Paulo Rouanet e Nelson Brissac Peixoto.

${ }^{4}$ Perfazendo o contexto no qual tem surgimento essa forma do morar, correlato de uma concepção da clínica que institui a casa como espaço identitário, de representação do eu e expressão simbólica de uma fantasmagoria pessoal, Baptista (2005) lança um alerta às abordagens que, no campo da saúde mental, investem de sacralidade o lugar da moradia, como o espaço interior que dá guarida à subjetividade. Para o autor, tanto quanto a cidade, a casa é potencialmente, não o espaço de confirmação da identidade, mas campo de experimentação de vida, de encontros, de sociabilidades, polissêmico, mutante e multifacetado.

5 "A decoração dos interiores defende-se contra a armadura de vidro e ferro com seus tecidos." (BENJAMIN, 2006, p. 252). Dando preferência ao veludo e à pelúcia, que conservam a marca de todo contato, o burguês nostálgico luta para preservar, na intimidade da sua morada, os rastros e as impressões de seus objetos de uso e de seus acessórios, que a vida privada na grande cidade fada ao desaparecimento. "A forma primeva de todo habitar é a existência não numa casa, mas num casulo. Este traz a impressão de seu morador. [...] O século XIX, como nenhum outro, tinha uma fixação pela moradia. Entendia a moradia como o estojo do homem, e o encaixava tão profundamente nela com todos os seus acessórios, que se poderia pensar no interior de um estojo de compasso, onde o instrumento se encontra depositado com todas as suas peças em profundas cavidades de veludo, geralmente de cor violeta. Não existiria um só objeto para o qual o século XIX não tenha inventado um estojo. Para relógios de bolso, chinelos, porta-ovos, termômetros, baralhos - e, na falta de estojos: capas protetoras, passadeiras, cobertas e guarda-pós. O século XX, com sua porosidade e transparência, seu gosto pela vida em plena luz e ao ar livre, pôs um fim à maneira antiga de habitar [...] e as dimensões do habitar se reduziram: para os vivos, com os quartos de hotel, para os mortos, com os crematórios." (BENJAMIN, 2006, p. 255).

${ }^{6}$ Somente em 1830, comenta Benjamin (2006), houve 6000 barricadas em Paris. Assim, Haussmann, "esse artiste démolisseur, como ele próprio se chamava, tinha em mente um embellissement stratégique, cujo objetivo era facilitar a movimentação de tropas das casernas aos bairros populares e dificultar a construção de barricadas pelo alargamento das ruas." (ROUANET, 1992, p. 55).

7 "Vidro que surge antes do seu tempo, ferro prematuro. O material mais frágil e o mais forte foram quebrados, por assim dizer, deflorados nas passagens. Em meados do século passado, ainda não se sabia como se devia construir com vidro e ferro. Por isso o dia que se infiltra do alto através das vidraças por entre suportes de ferro é tão sujo e nublado." (BENJAMIN, 2006, p. 189).

8 "Um Guia Ilustrado de Paris diz: "estas passagens, uma recente invenção do luxo industrial, são galerias cobertas de vidro e com paredes revestidas de mármore, que atravessam quarteirões inteiros, cujos proprietários se uniram para esse tipo de especulação. Em ambos os lados dessas galerias, que recebem a luz do alto, alinham-se as lojas mais elegantes, de modo que tal passagem é uma cidade, um mundo em miniatura." (BENJAMIN, 2006, p. 54-55). A maioria das passagens, informa Benjamin (BENJAMIN, 2006, p. 54-55), foram construídas entre 1822 e 1837, em decorrência do apogeu do comércio de tecidos. Já na cidade que o socialismo utópico de Fourier anteviu, organizada em comunidades igualitárias, as passagens perdiam sua função comercial para tornarem-se espaço de moradia. $\mathrm{O}$ falanstério, cidade de Fourier feita de passagens, adquire aparência de fantasmagoria. “A ‘cidade de passagem' é um sonho que deleitará o olhar dos 
parisienses até a segunda metade do século adentro. Ainda em 1869, as 'ruas galerias' de Fourier fornecem o traçado da utopia de Moilin, Paris en l'an 2000." (BENJAMIN, 2006, p. 56).

9 "O coletivo é um ser eternamente desperto, eternamente agitado, que vivencia, experimenta, reconhece e imagina tantas coisas entre as fachadas quanto os indivíduos no abrigo de suas quatro paredes. [...] A passagem é o seu salão. Nela, mais do que em qualquer outro lugar, a rua apresenta-se como o interior mobiliado e desgastado, habitado pelas massas." (BENJAMIN, 2006, p. 958; 1989, p. 194-195).

${ }^{10}$ Contudo, segue um Benjamin partidário da ação política, "só a revolução cria o ar livre da cidade", arrancando-a de seu sono entorpecedor (BENJAMIN, 2006, cf. infra).

${ }^{11}$ Contra o pessimismo de Adorno, afirma Gagnebin (2004, p. 30), Benjamin sempre insistirá nas perspectivas salvadoras que a crise da tradição - o desmoronar da identidade da linguagem, da história e do sujeito - pode oferecer à ação histórica dos homens: "através desse desmoronar [...] poderia talvez, enfim passar o sopro de uma palavra inteiramente redimida, que atravessa todas as línguas e pulveriza o peso do sentido, esta consumação silenciosa de todas as palavras humanas que Hölderlin, na sua 'loucura', teria ouvido, e que seria sua tradutibilidade integral." Nesse sentido, a idéia de redenção, em Benjamin, remete à noção de origem [Ursprung] não como início imaculado da história, mas como sua figura temporal, que só pode surgir e ser reconhecida através de uma luta obstinada: "porque, para serem salvos, os fenômenos devem ser arrancados - pelo conceito - a uma falsa continuidade, aquela que é abusivamente chamada objetiva, como se a cronologia não fosse, ela também, o fruto de uma construção historiográfica. [...] A obra de salvação do Ursprung é, portanto, ao mesmo tempo e inseparavelmente, obra de destituição e de restituição, de dispersão e de reunião, de destruição e de construção. [...] restauração do idêntico e emergência do diferente." (GAGNEBIN, 2004, p.16-18).

${ }^{12}$ Passagens é o título aferido para a edição brasileira da extensa e inacabada coletânea de fragmentos e citações sobre a Paris do século XIX de que se ocupou Benjamin desde 1927 até pouco antes da sua morte, em 1940, incluindo a produção de dois ensaios (exposés) sobre o tema, de 1935 e 1939, respectivamente. Conforme Bolle, organizador da publicação, os diferentes títulos que a edição desse material tem recebido - Das Passagen-Werk; Parigi, Capitale del XIX Secolo; Le Livre des Passagens; The Arcades Project - indicam o fato de que Benjamin não lhe propusera um título definitivo, ainda que, na maioria das vezes, a ele se referisse como Passagenarbeit, Trabalho das Passagens. A escolha brasileira, diz Bolle (BENJAMIN, 2006, p. 1144) concentra-se na palavra-chave do projeto de Benjamin, explorando as possibilidades semânticas que se abrem com o termo "passagens":

1) A referência topográfica, arquitetônica, urbanística e, com isso, a ambição de "representar a imagem do mundo" numa espécie de abreviatura monadológica. 2) A referência temporal, como passagem da era das revoluções para a era do capital e dos impérios, ou da iluminação com lamparinas de óleo a bicos de gás e as lâmpadas elétricas e, com isso, a simbolização do "efêmero" dos surrealistas e do próprio fluir ininterceptável da História. 3) A referência ao próprio modo de escrever a história da metrópole de Paris, de representar da forma mais concreta possível o labirinto urbano através de uma sintaxe enciclopédica de milhares de citações ou trechos ou "passagens", extraídas de centenas de livros.

No presente estudo, baseamo-nos especialmente na tradução estabelecida pela edição brasileira, confrontada à tradução francesa, Paris, capitale du XIX siècle - le livre des passages (Benjamin, 2000) e, quando pertinente, à tradução brasileira dos textos comuns que se encontram em Charles Baudelaire, um lírico no auge do capitalismo (BENJAMIN, 1989).

13 "No sonho, em que diante dos olhos de cada época surge em imagens a época seguinte, esta aparece associada a elementos da história primeva, ou seja, de uma sociedade sem classes. As experiências desta sociedade, que têm seu depósito no inconsciente do coletivo, geram, em interação com o novo, a utopia que deixou seu rastro em mil configurações da vida, das construções duradouras até as modas passageiras.” (BENJAMIN, 2006, p. 41). Esta formulação, presente no texto concluso (exposé) de 1935, não se repete no texto que Benjamin apresenta em 1939, possivelmente, como sugere Tiedemann (2006) e Nobre (1997), por força das críticas que então lhe dirige Adorno. Segundo Matos (2006, p. 1125), o otimismo histórico da primeira versão do ensaio cede lugar, na segunda versão, ao teor de resignação que a citação de Blanqui [L'Éternité par les Astres] e a fantasmagoria do século XIX incitam: monotonia e repetição cíclica, que Benjamin associa ao fetichismo da mercadoria ressaltado por Marx. Contudo, segundo Bolle (2006), cuja leitura coincide com a que propõe Gagnebin (nota anterior), Benjamin em nenhum momento renuncia ao aprofundamento das imagens dialéticas naquilo que ele denomina de inconsciente coletivo (ainda 
que venha a fazê-lo de modo mais comedido).

${ }^{14}$ Encontramos em Jacques (2006), na referência a uma história crítica do urbanismo, uma formulação que se aproxima da que propomos como experiência na clínica do AT. Diz ela: A cidade deixa de ser um simples cenário no momento em que ela é vivida, experimentada. Ela ganha corpo a partir do momento em que ela é praticada, se torna "outro" corpo. Para o errante urbano sua relação com a cidade seria da ordem da incorporação. Seria precisamente desta relação entre o corpo do cidadão e deste outro corpo urbano que poderia surgir uma outra forma de apreensão da cidade, uma outra forma de ação, através da experiência da errância - desorientada, lenta e incorporada[...](JACQUES, 2006, online).

${ }^{15}$ Ainda que, mais tarde, em Análise terminável e interminável, Freud (1976 [1937]) chegue à constatação de que a experiência transferencial foge do controle do amor, restrito a um sistema familiarista, aproximando-se antes ao dispositivo da guerra.

16 "Eu acredito que temos uma forma de criação, de depósito de criatividade, dos quais a principal característica é o que chamo de dessexualização do prazer. A idéia de que o prazer físico provém sempre do prazer sexual e a idéia de que o prazer sexual é a base de todos os prazeres possíveis, tem, penso eu, verdadeiramente algo de falso." (FOUCAULT, 2004 [1984], p. 264). Podemos ler essa afirmação de Foucault, por um lado, como uma crítica à apropriação do corpo pelo dispositivo da sexualidade, do qual a psicanálise é um dos operadores; por outro lado, ela prestase a uma leitura no interior da psicanálise mesma, se faz-se equivaler o sexual à ideia (falsa) de uma pulsão sexual total, para a qual convergeriam as pulsões parciais.

${ }^{17}$ Abstemo-nos de abordar as imprecisões na conceituação foucaultiana de prazer e suas diferenças com respeito ao conceito de prazer em Freud, bem como sua recusa da noção de desejo, da qual se valem Lacan, numa perspectiva, e Deleuze e Guattari, em outra. Conforme a leitura de Ortega (2000), interessa-nos sublinhar o caráter absolutamente aberto com que a amizade, na concepção de Foucault, pode tomar forma.

${ }^{18}$ Em outro estudo, citado acima (PALOMBINI. 2002), numa visada psicanalítica, fizemos referência à ameaça que freqüentemente representa a presença do ou da acompanhante perante uma relação constituída num continuum entre mãe e filho. A mãe, então, antecipando-se a qualquer possibilidade de confrontação do filho ou filha com o Outro sexo (condição sine qua non, para a psicanálise, da passagem adolescente), dentre outras atitudes podia servir-se dessa de que se vale a mãe de Artur, ou seja, tratar de apresentar a acompanhante como objeto de um gozo aludido (mas que, ao ser dessa forma oferecido pela mão da mãe, deixava de ser signo da diferença sexual, tornando-se extensão de seu próprio corpo - era a mãe que ali se oferecia). Na perspectiva foucaultiana da amizade, porém, o que se trata de ressaltar é o quanto o aprisionamento de Artur no caráter sexual da relação almejada (e fracassada) com sua "at", que respondia ao desejo de sua mãe, impedia-lhe de seguir experimentando outras formas de relação e prazer.

${ }^{19}$ Tal ênfase parece-nos tributária do movimento que, no Brasil, desde os anos 1980, propulsiona o processo de reforma psiquiátrica brasileira imprimindo-lhe a perspectiva desinstitucionalizante e de vinculação capilar com a cidade que tem origem na proposta basagliana, sem exclusão, porém, das influências próprias ao campo da clínica psicanalítica.

${ }^{20} \mathrm{~A}$ aparente uniformidade com que a rua é apresentada, porém, não esconde os tensionamentos que lhe são próprios e que se lê nas entrelinhas do texto, como sugere, por exemplo, a referência ao paciente que obtém um sanduíche fora de linha no McDonald's (PORTO; SERENO, 1991), impondo sua diferença à lógica da uniformização e da velocidade que caracterizam as relações de mercado; ou que emerge no questionamento que um dos autores (CESARINO, 1991), desde o campo da saúde pública, lança aos acompanhantes que, no livro, referem-se à rua, em oposição a casa, como o outro, o estranho, o "lado de lá", sem atenção às diferenças que se apresentam com respeito ao modo de experimentar a rua conforme as classes sociais em questão.

${ }^{21} \mathrm{O}$ relato que Ricardo André Cecchin (2008), acompanhante terapêutico, faz dessa cena encontrase no vídeo Cadê o AT? Em busca de um companheirismo amigo, produzido pela Oficina de Imagens do CAPS CAIS Mental Centro, vinculado à Secretaria de Saúde de Porto Alegre, para exibição durante o III Congresso Internacional de Acompanhamento Terapêutico, realizado em outubro de 2008 em Porto Alegre. 


\section{REFERÊNCIAS}

ARAÚJO, F. Um passeio esquizo pelo acompanhamento terapêutico: dos especialismos clínicos à política da amizade. 2005. Dissertação (Mestrado em Estudos da Subjetividade)-Universidade Federal Fluminense, Niterói, RJ, 2005.

BAPTISTA, L. A. S. Dispositivos residenciais e as máquinas do morar. In: JACÓVILELA, A. M.; CEREZZO, A. C.; RODRIGUES, H. B. (Org.). ENCONTRO CLIO-PSYCHÉ - HISTÓRIA E MEMÓRIA. 4., 2001, Rio de Janeiro. Anais... Juiz de Fora: Clioedel - Clio Edições Eletrônicas, 2005, p. 71-79.

BAUDELAIRE, C. O cisne (1860). In: . As flores do mal (edição bilingue). Rio de Janeiro: Nova Fronteira, 1985, p. 324-329; p. 606-607 (notas).

BELLOC, M. M. Ato criativo e cumplicidade. 2005. Dissertação (Mestrado em Artes Visuais)-Universidade Federal do Rio Grande do Sul, Porto Alegre, 2005.

BENJAMIN, W. Passagens. Belo Horizonte: UFMG, 2006. 1.167p.

2000.

. Paris, capitale du XIXe. Siècle: le livre des passages. 3. ed. Paris: CERF,

. Rua de mão única (1987). 5. ed. São Paulo: Brasiliense, 1995. Obras escolhidas, v. 2.

. Charles Baudelaire um lírico no auge do capitalismo. São Paulo: Brasiliense, 1989. Obras escolhidas, v. 3.

BOLLE, W. 'Um painel com milhares de lâmpadas' Metrópole \& Megacidade. Posfácio. In: . Passagens. Belo Horizonte: UFMG, 2006. p. 1141-1167.

CABRAL, K. V. Acompanhamento terapêutico como dispositivo da reforma psiquiátrica: considerações sobre o setting. 2005. Dissertação (Mestrado em Psicologia Social e Institucional)-Universidade Federal do Rio Grande do Sul, Porto Alegre, 2005.

CALVINO, I. As cidades invisiveis (1972). São Paulo: Companhia das Letras, 1990.

CAPELLA. N. Prática em Acompanhamento Terapêutico: claudicantes limites do AT. Trabalho de conclusão do estágio em acompanhamento terapêutico. Instituto de Psicologia da Universidade Federal do Rio Grande do Sul, Porto Alegre, 2008. Mimeografado. 
CECCHIN. R. A. Depoimento. In: . CADÊ o AT? Em busca de um companheirismo amigo. Porto Alegre, OFICINA DE IMAGENS CAPS CAIS MENTAL CENTRO, 2008. 1 DVD. Vídeo exibido durante o III Congresso Internacional de Acompanhamento Terapêutico, realizado em outubro de 2008 em Porto Alegre.

CERTEAU, M. A invenção do cotidiano: artes de fazer. 10. ed. Petrópolis: Vozes, 1994. v. 1.

CESARINO, A. C. A rua e o social de cada um. In: . A rua como espaço clínico: acompanhamento terapêutico. São Paulo: Escuta, 1991. p.109-118.

D'ANGELO, M. A modernidade pelo olhar de Walter Benjamin. Estudos Avançados, São Paulo, v. 20, n. 56, 2006. Disponível em $<$ http://test.scielo.br/ scielo.php?script $=$ sci arttext\&pid $=$ S0103-40142006000100016\&lng=en\&nrm= iso >. Acesso em 04 out. 2006.

DERRIDA, J. Políticas de la amistad (seguido de El oído de Heidegger). Madri: Trotta, 1998, p. 11-338.

. Papel-máquina. São Paulo: Estação Liberdade, 2004.

EQUIPE de Acompanhantes Terapêuticos do Hospital-Dia A Casa (Org.). A rua como espaço clínico: acompanhamento terapêutico. São Paulo: Escuta, 1991.

. Crise e cidade: acompanhamento terapêutico. São Paulo: EDUC, 1997.

FONSECA, R. A arte de andar nas ruas do Rio de Janeiro (1992). In:

Romance negro e outras histórias. 2. ed. São Paulo: Companhia das Letras, 2004. p. $9-50$.

FOUCAULT, M. De l'amitié comme mode de vie (1981). In: . Dits et écrits: entrevista de Michel Foucault a R. de Ceccaty, J. Danet e J. le Bitoux. Paris: Gallimard, 1994. v. IV. Disponível em $<$ http://www.unb.br/fe/tef/filoesco/ foucault/amitie.html>. Acesso em: 25 nov. 2005.

.Michel Foucault, uma entrevista: sexo, poder e a política da identidade (1984). Verve, São Paulo, n. 5, p. 260-277, 2004. Entrevistadores: B. Gallagher e A. Wilson, Toronto, 1982. Disponível em <http://www.nu-sol.org/verve/pdf/ verve5.pdf $>$. Acesso em 23/12/2006.

FRAYZE-PEREIRA, J. A. Crise e cidade: por uma poética do acompanhamento terapêutico. In: EQUIPE de Acompanhantes Terapêuticos do Hospital-Dia A Casa (Org.). Crise e cidade: acompanhamento terapêutico. São Paulo: EDUC, 1997, p. 19-35. 
FREUD, S. Observações sobre o amor transferencial: novas recomendações sobre a técnica da psicanálise III (1915). In: - Obras psicológicas completas. Rio de Janeiro: Imago, 1976. v. 12, p. 205-223. Edição Standard Brasileira.

. Análise terminável e interminável (1937). In: . Obras psicológicas completas. Rio de Janeiro: Imago, 1976. v. XXIII, p. 239-287. Edição Standard Brasileira

GAGNEBIN, J. M. História e narração em Walter Benjamin. 2. ed. São Paulo: Perspectiva, 2004.

ISIDRO, V. F.; SILVA, S. C. Relatório final do acompanhamento terapêutico. Trabalho de conclusão de estágio. Departamento de Psicologia. Universidade Federal Fluminense, Niterói, 2006.

JACQUES, P. B. Elogio aos errantes: a arte de se perder. ReverberAções 2006. Disponível em: $<$ http://www.corocoletivo.org/reverberacoes/publicacao. htm\#elogio >. Acesso em: 10 fev. 2007.

JOVER, E. R. Tropeços e pegadas de uma caminhada pelo centro. In: Acompanhamento terapêutico na rede pública: a clínica em movimento. Porto Alegre: UFRGS, 2004. p. 65-70.

MATOS, O. C. F. Aufklärung na metrópole: Paris e a Via Láctea. Posfácio. In: . Passagens. Belo Horizonte: UFMG; São Paulo: Imprensa Oficial do Estado de São Paulo, 2006, p. 1123-1140.

NOBRE, M. Objeções marxistas? Adorno e Benjamin na 'encruzilhada de magia e positivismo' dos anos 30. Cadernos de filosofia alemã, São Paulo, v. 3, p. 4559, 1997.

ORTEGA, F. Para uma política da amizade: Arendt, Derrida, Foucault. Rio de Janeiro: Relume-Dumará, 2000. Coleção Conexões, v. 6.

PALOMBINI, A. L. Passagens obstruídas: quartos privativos, mínimas janelas. Revista da Associação Psicanalítica de Porto Alegre. Clínica da adolescência. Porto Alegre, n.23, p. 63-68, jun. 2002.

PICOLLI, L. F. Relato de estágio em acompanhamento terapêutico. Trabalho de conclusão do estágio em acompanhamento terapêutico. Instituto de Psicologia da Universidade Federal do Rio Grande do Sul, Porto Alegre, 2008.

POE, E. A. O homem da multidão (1850). Porto Alegre: Paraula, 1993. Edição Trilíngue incluindo a tradução francesa de Charles Baudelaire e notas de Walter Benjamin. 
PORTO, M. A polis arquipélago: notas do acompanhamento terapêutico. In: CONGRESSO INTERNACIONAL DE ACOMPANHAMENTO TERAPÊUTICO, 3., 2008, Porto Alegre. Simpósio Temático As cidades do AT, Porto Alegre: [S.1.], 2008.

PORTO, M.; SERENO, D. Sobre acompanhamento terapêutico. In: . A rua como espaço clínico: acompanhamento terapêutico. São Paulo: Escuta, 1991. p. 23-31.

REIS NETO, R. O. Acompanhamento terapêutico: emergência e trajetória histórica de uma prática em saúde mental no Rio de Janeiro. 1995. Dissertação (Mestrado em Psicologia Clínica)-Pontifícia Universidade Católica do Rio de Janeiro, Rio de Janeiro, 1995.

REVISTA USP. Dossiê Walter Benjamin. São Paulo, n.15, p.49-72, set-nov 1992.

ROUANET, S. P. É a cidade que habita os homens ou são eles que moram nela? Revista USP. Dossiê Walter Benjamin. São Paulo, n.15, p.49-72, set-nov 1992.

SENNETT, R. Carne e Pedra: o corpo e a cidade na civilização ocidental. Rio de Janeiro: Record, 1997.

SOUSA. E. L.A. Uma ronda utópica. Zero Hora, Porto Alegre, 18 de abril de 2009. Caderno Cultura, p. 2.

TIBULO, A. P. Estudo de caso. Trabalho de conclusão do estágio em acompanhamento terapêutico. Instituto de Psicologia da Universidade Federal do Rio Grande do Sul, Porto Alegre, 2003. Mimeografado.

TIEDEMANN, R. Introdução à edição alemã (1982). In: BENJAMIN, W. Passagens. Belo Horizonte: UFMG, 2006. p. 13-35.

Recebido em: junho de 2009

Aceito em: agosto de 2009 